\title{
AS CIDADES PEQUENAS NA GEOGRAFIA BRASILEIRA: A CONSTRUÇÃo DE UMA AGENDA DE PESQUISA
}

Orlando Moreira Junior*

Resumo: Este texto discute a abordagem que o tema cidades pequenas vem ganhando na ciência geográfica brasileira, a partir do levantamento feito nos anais do Encontro Nacional de Geógrafos, entre os anos de 2000 e 2010. Com base nestes, é possível observar que se destacam dois eixos na abordagem do tema. Um que prioriza a análise dos efeitos externos na compreensão das cidades pequenas, e outro focalizado na compreensão da dinâmica interna do tecido urbano.

Palavras-chave: Geografia, cidades pequenas, desafios, efeitos externos, dinâmica intraurbana.

\section{SMALL CITIES IN BRAZIL GEOGRAPHY: BUILDING A RESEARCH AGENDA}

Abstract: This paper addresses the discussion that the issue is gaining in small towns Brazilian geographical science, based on the survey in the annals of Geographers National Meeting, between the years 2000 and 2010. Based on these, it is possible to observe two axes that stand in addressing the issue. The first priority to the analysis of external effects in the understanding of small towns, and the second focuses on the analysis of the internal dynamics of the city.

Keywords: Geography, small towns, challenges, external effects, intra-urban dynamics.

\section{Introdução}

Este texto é um ponto de partida. As ideias expostas aqui representam parte da discussão acerca das cidades pequenas no âmbito da ciência geográfica brasileira. Assim, o objetivo principal desta análise é refletir sobre o vislumbrar das cidades pequenas na Geografia nacional. Para tanto, como forma de possibilitar a construção de um pensamento sobre a temática foi realizado um levantamento sobre a produção geográfica referente ao tema nos anais dos Encontros Nacionais de Geógrafos (ENG) no período de 2000 a 2010.

Duas ideias principais norteiam este ensaio. A primeira é confirmar que os estudos a respeito das cidades pequenas não têm sido privilegiados no cenário acadêmico. A produção de conhecimento, tanto em nível empírico quanto teórico, em torno dessa categoria de cidade esteve à margem da produção geográfica. No Brasil, de maneira geral, os estudos sobre os espaços urbanos sempre privilegiaram as abordagens sobre metrópoles, cidades grandes e médias.

Por outro lado, a segunda ideia abrange os avanços teóricos e metodológicos na busca do entendimento deste perfil de cidades. Afinal, esta outra face do urbano brasileiro não pode ser abandonada e deve constar nas pautas acadêmicas e políticas.

Como cabe à Geografia analisar e compreender a organização do espaço, a intenção inicial foi pensar sobre a produção geográfica acerca da temática das cidades pequenas. Se a opção pelos anais revela com maior exatidão a amplitude que o tema ganha no cenário da Geografia brasileira -

* Doutorando em Geografia pelo IGCE-Unesp. E-mail: orlandomoreirajunior@yahoo.com.br. 
com trabalhos sobre diversas regiões do país -, outras fontes bibliográficas não podem ser esquecidas.

É possível encontrar artigos sobre cidades pequenas em diferentes periódicos (FABRINI, 2009; CORRÊA, 2011; GOMES et. al., 2005; entre outros). Em alguns dos principais Programas de Pós-Graduação em Geografia do país, Dissertações e Teses, também tem apreciado o tema (CRIVELARO, 2008; BACELAR， 2008; MELO， 2008; ANDRADE， 2001; BERNARDELLI， 2004; ENDLICH，2006; ROMA, 2008; FIGUEIREDO, 2008); entre outros). Além de livros de Geografia, que versam especificamente sobre a temática das cidades pequenas (ENDLICH, 2009; LOPES; HENRIQUE, 2010).

Todavia a opção pelos anais se justifica por duas motivações básicas. Primeiramente, a continuidade, ou seja, revela tanto a ocorrência do tema no pensamento geográfico brasileiro quanto a permanência progressiva de questionamentos sobre a temática sob o olhar do geógrafo. Em segundo lugar, por ser um evento de nível nacional, o que permite a exposição de variados cenários e possibilidades diversas de leituras acerca das cidades pequenas.

\section{Cidades pequenas, pequenas cidades ou cidades locais?}

Essa é uma questão complexa, assim como é difícil notar um consenso entre os trabalhos realizados acerca do tema. Essa complexidade se reflete também nos desafios teóricos e metodológicos que os pesquisadores se deparam na leitura das cidades pequenas. Isso se deve principalmente ao fato de que, no caso dessa tipologia de cidades, no Brasil, há núcleos urbanos com menos de mil habitantes, bem como alguns casos particulares de cidades que chegam a ultrapassar $50 \mathrm{mil}$ que adquirem características de cidades locais na rede urbana.

Da mesma forma, há cidades com cerca de 50 mil habitantes com características de uma cidade média em regiões de baixa densidade demográfica. Transmitindo para o cenário nacional, seria o mesmo que dizer que existem diferenças consideráveis entre cidades pequenas do Sudeste e do Norte do país, por exemplo. Assim também há diferenças entre cidades pequenas antigas e novas; entre aquelas inseridas em áreas metropolitanas e não metropolitanas.

Santos (1994), entre outros, usa o conceito de cidade local com base no grau, na intensidade e na abrangência da centralidade desempenhada por estas cidades. Nesta direção é valido salientar que cidades pequenas e cidades locais não devem ser vistas enquanto sinônimos, conforme esclarece Fresca (2010). Cidade local referese ao menor escalão das cidades no Brasil; cidades que atendem apenas as demandas mais imediatas de sua população. Já a cidade pequena seria aquela com complexidade de atividades urbanas que extrapola o denominado nível mínimo, mas que tal complexidade de atividades urbanas não gera elementos necessários para que as mesmas possam ser consideradas cidades intermediárias.

Entretanto, deve-se considerar que a cidade local tende a ser uma cidade pequena. Por isso a defesa de atribuir à palavra "cidade" um papel substantivo, devido seu 
caráter de ser urbano, ao mesmo tempo em que recebe uma qualidade: ser pequena, tanto espacial quanto demograficamente. Deste modo, durante o levantamento nos eram denominadas de cidades pequenas, pequenas cidades ou cidades locais.

\section{As cidades pequenas na produção atual da Geografia}

Os anais do Encontro Nacional de Geógrafos representam uma forma eficiente de comunicação do conhecimento e do desenvolvimento da ciência. Constituem-se como fonte importante na busca, apreensão e transmissão de novos conhecimentos. Além anais foram elencados os trabalhos que propunham o estudo desta tipologia de cidades, indiferentemente se de permitir o acesso a informações atualizadas, também possibilitam, por um lado, uma leitura em nível nacional sobre o tema e, por outro, quantificar o número de pesquisas envolvendo cidades pequenas que se vêm produzindo em Geografia.

$\mathrm{Na}$ Tabela 1, apresentam-se o ano e o local onde ocorreu o evento, juntamente com os autores e seus respectivos trabalhos registrados nos anais. Ressalte-se que, em 2004, aconteceu o VII Congresso Brasileiro de Geógrafos, que ocorre a cada dez anos e substitui o ENG.

Tabela 1 - Trabalhos apresentados nos ENGs e no VII Congresso Brasileiro de Geógrafos, entre os anos de 2000 e 2010

\begin{tabular}{|c|c|c|}
\hline $\begin{array}{l}\text { evento/ } \\
\text { ano }\end{array}$ & título do trabalho & autor(es) \\
\hline \multirow{3}{*}{ 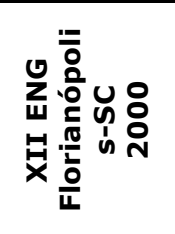 } & $\begin{array}{l}\text { Os papéis urbanos na região de Catanduva-SP: relações entre a } \\
\text { produção de moradias e o trabalho volante }\end{array}$ & BERNARDELLI \\
\hline & $\begin{array}{l}\text { O geoprocessamento como ferramenta de gestão urbana de } \\
\text { cidades pequenas }\end{array}$ & CHAGAS et. al. \\
\hline & $\begin{array}{c}\text { Cidades locais: importância para o desenvolvimento do Triângulo } \\
\text { Mineiro e Alto Paranaíba-MG }\end{array}$ & OLIVEIRA; SOARES \\
\hline \multirow{6}{*}{ 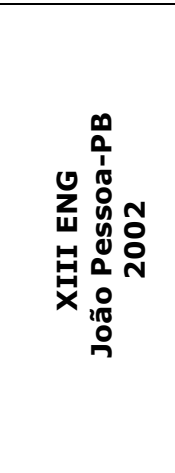 } & $\begin{array}{l}\text { O clima das cidades tropicais de pequeno porte na região } \\
\text { sudoeste de Mato Grosso: Pedra Preta, Dom Aquino e Guiratinga }\end{array}$ & SILVA, A. L. et. al. \\
\hline & $\begin{array}{l}\text { A cidade pequena e sua participação na organização espacial } \\
\text { regional: um estudo de sustentabilidade ambiental em Estrelado } \\
\text { Sul-MG }\end{array}$ & MICHELOTTO et. al. \\
\hline & $\begin{array}{l}\text { A importância das cidades medias e locais na dinâmica urbana da } \\
\text { bacia do rio Araguari-Minas Gerais }\end{array}$ & ENGEL et. al. \\
\hline & Cidades locais do Cerrado mineiro: uma leitura preliminar & BORGES; SOARES \\
\hline & $\begin{array}{l}\text { Os papéis urbanos na região de Catanduva - SP: relações entre a } \\
\text { produção de moradias e o trabalho volante }\end{array}$ & BERNARDELLI \\
\hline & $\begin{array}{l}\text { Rede urbana, urbanidades e as pequenas cidades: ensaiando a } \\
\text { discussão }\end{array}$ & ENDLICH \\
\hline \multirow{5}{*}{ 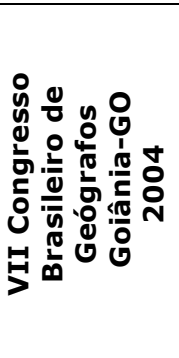 } & Para entender as cidades pequenas: contribuições para o debate & GONÇALVES; COSTA \\
\hline & $\begin{array}{l}\text { A dinâmica urbana das pequenas cidades do cerrado mineiro e } \\
\text { sua participação na rede urbana regional }\end{array}$ & ENGEL; SOARES \\
\hline & $\begin{array}{l}\text { Gestão pública nas pequenas cidades do Rio Grande do Norte na } \\
\text { era da informação }\end{array}$ & GOMES et. al. \\
\hline & $\begin{array}{l}\text { A modernidade nos espaços rural e urbano das pequenas cidades } \\
\text { do cerrado mineiro: estudo em Tupaciguara - Minas Gerais }\end{array}$ & BRIDI; SOARES \\
\hline & $\begin{array}{l}\text { A questão do lugar para a compreensão da vida cotidiana em } \\
\text { Regente Feijó: uma análise em cidades pequenas }\end{array}$ & SANT'ANA \\
\hline
\end{tabular}




\begin{tabular}{|c|c|c|}
\hline $\begin{array}{l}\text { evento/ } \\
\text { ano }\end{array}$ & título do trabalho & autor(es) \\
\hline \multirow{7}{*}{ 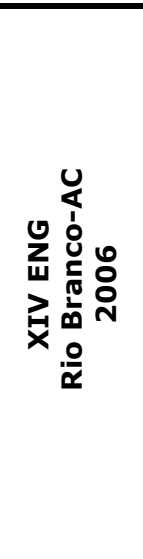 } & $\begin{array}{l}\text { A dinâmica econômica em cidades pequenas: estudo de caso de } \\
\text { Ouro Verde/SP. }\end{array}$ & LEÃO; SPOSITO \\
\hline & $\begin{array}{l}\text { A gestão do território no contexto da redemocratização do Brasil: } \\
\text { um olhar sobre as pequenas cidades do cariri paraibano }\end{array}$ & SILVA, A. B. \\
\hline & Segregação socioespacial em cidades pequenas & ROMA \\
\hline & $\begin{array}{l}\text { Cidades pequenas não devem ser consideradas urbanas? O caso } \\
\text { de Novo Triunfo/Bahia }\end{array}$ & LOPES \\
\hline & $\begin{array}{l}\text { Um olhar sobre a urbanização, seus problemas e o planejamento } \\
\text { das cidades locais. Estudo de caso da cidade de Jaguaruna/SC }\end{array}$ & DELFINO; DIAS \\
\hline & $\begin{array}{c}\text { Planejamento, gestão do território e desenvolvimento } \\
\text { socioespacial das pequenas cidades do Rio Grande do Norte }\end{array}$ & GOMES et. al. \\
\hline & $\begin{array}{c}\text { O processo de redefinição do espaço urbano em uma cidade de } \\
\text { pequeno porte: uma análise do Conjunto Habitacional Catulino } \\
\text { Rodrigues de Lima em Rio Brilhante/MS }\end{array}$ & DOMINGUES et. al. \\
\hline \multirow{10}{*}{ 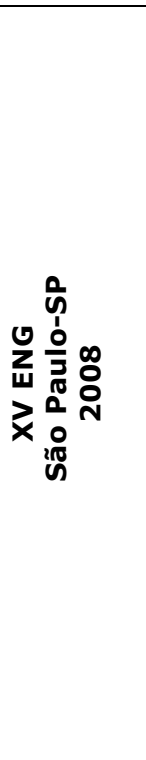 } & $\begin{array}{c}\text { Existe segregação socioespacial em municípios pequenos?O caso } \\
\text { de Forquilhinha (SC) }\end{array}$ & LAHORGUE et. al. \\
\hline & $\begin{array}{l}\text { Reflexões sobre as pequenas cidades do norte de Minas Gerais } \\
\text { (BR) }\end{array}$ & PEREIRA \\
\hline & $\begin{array}{l}\text { Pequenas cidades no vale do Ivinhema - MS: papéis urbanos, } \\
\text { reprodução social e produção de moradias }\end{array}$ & $\begin{array}{r}\text { BERNARDELLI; } \\
\text { MATUSHIMA }\end{array}$ \\
\hline & $\begin{array}{c}\text { Cidade e dinâmica cultural: o contexto das cidades locais da } \\
\text { microrregião Ceres, Goiás }\end{array}$ & CASTILHO; CHAVEIRO \\
\hline & $\begin{array}{l}\text { Processos excludentes em pequenas cidades paulistas - a } \\
\text { modelização cartográfica em Álvares Machado - SP }\end{array}$ & ROSSI; MARTINUCI \\
\hline & $\begin{array}{c}\text { Entre o rural e o urbano: cidades locais no CONSAD Paraná } \\
\text { Centro - PR }\end{array}$ & QUEIROZ \\
\hline & Astolfo Dutra: dinâmica industrial de uma cidade local & DEFILIPPO et. al. \\
\hline & $\begin{array}{l}\text { Reconstituindo o estudo das cidades de pequeno porte na } \\
\text { Geografia urbana brasileira }\end{array}$ & MEDEIROS et. al. \\
\hline & $\begin{array}{l}\text { Pequenas cidades da microrregião de Catalão (GO): papel dos } \\
\text { processos de "modernização" econômica na dinâmica urbana }\end{array}$ & MELO; SOARES \\
\hline & $\begin{array}{c}\text { Interações espaciais em cidades pequenas e médias: o caso do } \\
\text { processo de aglomeração urbana }\end{array}$ & MIYAZAKI \\
\hline \multirow{11}{*}{ 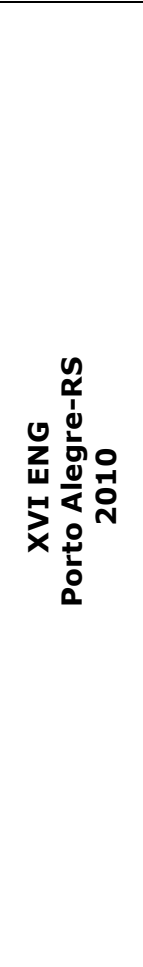 } & $\begin{array}{l}\text { Perfil socioeconômico das cidades pequenas do seridó ocidental } \\
\text { da Paraíba }\end{array}$ & CAVALCANTE \\
\hline & $\begin{array}{l}\text { O uso do espaço pelas vaquejadas em cidades pequenas: o caso } \\
\text { de Santo Antônio no Rio Grande do Norte }\end{array}$ & SILVA, G. \\
\hline & $\begin{array}{c}\text { Produção do espaço urbano, reprodução social da moradia e } \\
\text { desigualdades socioespaciais em cidades pequenas paulistas: os } \\
\text { casos de Capão Bonito e Buri }\end{array}$ & MOREIRA JUNIOR \\
\hline & $\begin{array}{l}\text { Análise da variabilidade termal nas cidades de pequeno e médio } \\
\text { porte paulista: o caso de Presidente Prudente e Votuporanga - } \\
\text { SP (1976-2009) }\end{array}$ & FANTE \\
\hline & $\begin{array}{c}\text { Pequenas cidades ou cidades locais? Por uma perspectiva } \\
\text { teórico-metodológica atual }\end{array}$ & CASARIL \\
\hline & $\begin{array}{c}\text { Pequena cidade: caracterização e conceituação pelo ponto de } \\
\text { vista político-administrativo }\end{array}$ & BACELAR \\
\hline & $\begin{array}{l}\text { Reflexões sobre o papel do planejamento urbano na pequena } \\
\text { cidade de Rio de Contas/BA }\end{array}$ & DIAS \\
\hline & $\begin{array}{c}\text { O turismo como subsídio para o desenvolvimento de pequenas } \\
\text { cidades do norte de Minas Gerais }\end{array}$ & SILVEIRA \\
\hline & $\begin{array}{c}\text { Segregação em pequenas cidades: um estudo de caso na cidade } \\
\text { de Anadia Alagoas }\end{array}$ & VIEIRA \\
\hline & $\begin{array}{l}\text { Serviços especializados como nova inserção na divisão do } \\
\text { trabalho em pequenas cidades: o caso de Santa Fé - PR }\end{array}$ & VEIGA \\
\hline & $\begin{array}{c}\text { Os rondonistas e os desafios na elaboração de propostas de } \\
\text { contribuição para o plano diretor de pequenas cidades do interior } \\
\text { do país }\end{array}$ & SILVA, L. \\
\hline
\end{tabular}




\begin{tabular}{|c|c|c|}
\hline $\begin{array}{c}\text { evento/ } \\
\text { ano }\end{array}$ & título do trabalho & autor(es) \\
\hline \multirow{5}{*}{ 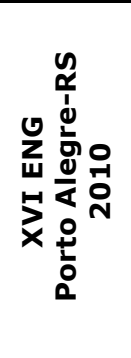 } & $\begin{array}{l}\text { Territorialidades e espaço público em pequenas cidades da } \\
\text { fronteira amazônica: reflexões sobre Oiapoque - AP }\end{array}$ & SANTOS \\
\hline & $\begin{array}{c}\text { Pequenas cidades e produção territorial: elementos para a } \\
\text { discussão geográfica }\end{array}$ & CHAGAS \\
\hline & Centros locais e pequenas cidades: distinções necessárias & FRESCA \\
\hline & $\begin{array}{l}\text { Produção industrial em pequenas cidades e reinserções na rede } \\
\text { urbana: o caso de Assai - PR }\end{array}$ & ALMEIDA \\
\hline & $\begin{array}{l}\text { O uso das ferramentas de geoinformação nas políticas públicas } \\
\text { sociais em municípios de pequeno porte }\end{array}$ & MARTINUCI \\
\hline
\end{tabular}

Fonte: Anais do ENG (2000; 2002; 2006; 2008; 2010) e VII Congresso Brasileiro de Geógrafos (2004). Organização: Orlando Moreira Junior, 2012.

É notável que, no período analisado, houve um crescimento gradual do número de trabalhos completos envolvendo o tema das cidades pequenas, como mostra a Figura 1. Contudo, apesar deste relativo aumento, sua relevância acadêmica ainda tem reduzida expressão, pois ainda representam uma parcela pequena em vista do número total de trabalhos publicado em cada edição deste evento científico.

Figura 1 - Número de trabalhos completos publicados nos ENGs (2000 a 2010)

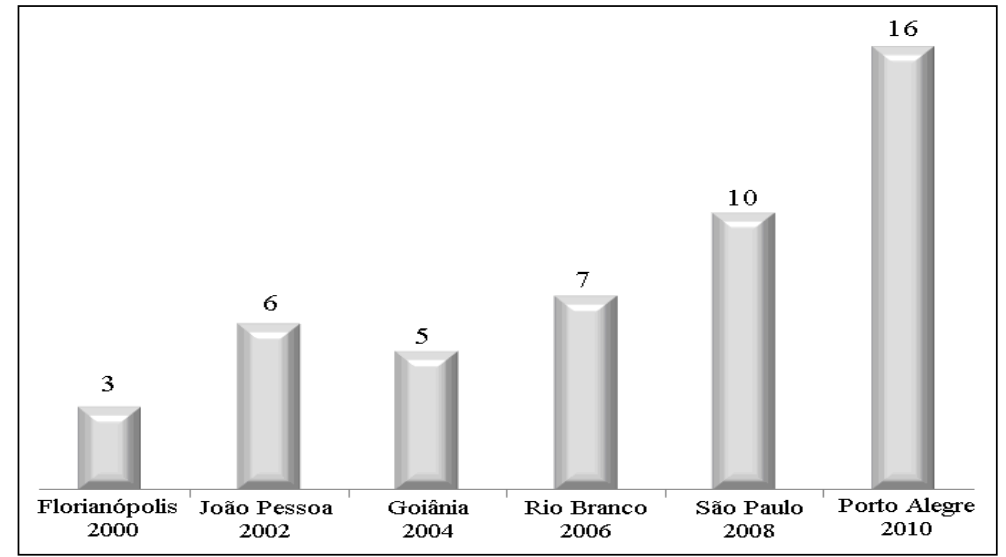

Fonte: Pesquisa direta nos anais dos eventos.

No Brasil, a discussão sobre o tema é variada, e as análises procuram responder a variáveis relativas ao tamanho da populaçào, a critérios econômicos e a funções urbanas, por exemplo. A partir disso, os trabalhos desmembram-se em outras classes temáticas, nas quais se podem enquadrar. Com base nisso, é possível estabelecer seis classes temáticas principais para o estudo da temática urbana:
- Estrutura territorial, redes e escalas: o atual contexto de reestruturação produtiva e reorganização da ocupação do território e dos fluxos de pessoas, mercadorias e informações concorrem para a construção de novas interações socioespaciais, que articulam diferentes escalas, contribuindo para reconfigurar dinâmicas territoriais e redefinem a rede urbana e o papel da urbanização e das cidades; 
- Desenvolvimento regional e pactos territoriais: estudos que analisam, problematizam e procuram desvendar os atores políticos, agentes econômicos e instrumentos de desenvolvimento que atuam na constituição de redes regionais, circuitos produtivos e reorganização do espaço;

- Políticas públicas, gestão do território e planejamento urbano e regional: as políticas públicas, as atividades de planejamento e a gestão do território contribuem para reconfigurar dinâmicas espaciais e interferem nas formas de organização e de desenvolvimento dos espaços;

- Processos e transformações na configuração dos espaços urbanos: estudos centrados na produção da cidade, suas transformações e permanências, seja a partir das dimensões morfológicas ou a partir das políticas, dos interesses e dos agentes envolvidos no processo de apropriação e produção dos espaços urbanos;

- Ambiente e sociedade: as novas escalas das questões ambientais e os dilemas, tensões e incertezas em relação aos atuais modos de apropriação e produção do espaço e do uso dos recursos ambientais, bem como as abordagens sob o viés da sustentabilidade;

- Discussão conceitual e questões teórico-metodológicas: engloba as investigações que procuram tecer uma definição ao termo cidade pequena ou mesmo apresentar um esforço e possibilidades para uma possível conceituação, assim como aproximações e distinções metodológicas.
O levantamento efetuado expressa um vislumbrar da preocupação acadêmica brasileira sobre uma face do urbano ainda pouco investigada pela Geografia. Ao mesmo tempo, permite verificar diversos desafios e incertezas presentes nos estudos que tem como referencial empírico as cidades pequenas.

O primeiro está relacionado à dificuldade em se conceber uma reflexão sobre as cidades pequenas sem considerar o cenário no qual ela está inserida. Nesta direção muitos trabalhos visam traçar relações entre os centros urbanos e seu entorno rural e as ruralidades que marcam o modo de vida nestas cidades. Em outros casos, analisa-se a dependência em relação ao contexto urbano e regional circundante. Esta perspectiva engloba também a análise da hierarquia urbana e as estratégias de planejamento e gestão do território.

O segundo desafio diz respeito ao tamanho demográfico e sua importância na delimitação das cidades pequenas. É utilizado por muitos como único critério para classificação do que seria uma cidade pequena, enquanto que outros trabalhos consideram este como um dentre outros fatores para tal definição. De qualquer forma, isso representa uma ampla possibilidade que se abre em relação à caracterização das cidades pequenas a partir do seu tamanho populacional. Há trabalhos que classificam as cidades pequenas como aquelas com até 2.000 habitantes, outros até 10.000, 20.000, 50.0000 , ao mesmo tempo em que há casos que apontam aqueles núcleos urbanos com população entre 50.000 e 100.000 habitantes. 
O terceiro desafio e incerteza envolve a localização. As cidades, historicamente, sempre representaram uma das formas de concretizar a ocupação do espaço nacional. As cidades brasileiras apresentam diferentes tamanhos, populacionais e territoriais, que desempenham papéis distintos na rede urbana e estabelecem diferentes níveis de interdependência entre si e em relação ao campo. A localização geográfica pode diferir em suas funções urbanas e no papel que ela desempenha na rede urbana. Como exemplo, podem-se citar as diferenças entre as cidades pequenas localizadas em áreas metropolitanas e aquelas que se encontram em áreas não metropolitanas; ou as diferenças entre cidades localizadas em áreas densamente povoadas e aquelas encontradas em regiões com baixa densidade demográfica.

O quarto desafio, notável entre os trabalhos encontrados na pesquisa bibliográfica é a dificuldade em se estabelecer, quantitativa e qualitativamente, uma definição precisa para cidade pequena. Sendo que, em diversos trabalhos, é possível verificar uma confusão conceitual entre cidade e município, onde ambos os termos são tratados, erroneamente, como sinônimos.

Os desafios são, portanto, diversos e, em certa medida, estão diretamente relacionados: contribuir para dotar a noção de "cidade pequena" de um conteúdo teórico-conceitual. Conceituar cidade pequena é uma tarefa de difícil elaboração que gera uma série de questionamentos. No caso das cidades médias, por exemplo, os critérios de classificação baseados no tamanho demográfico e na localização são os mais utilizados, ao menos como primeira aproximação, para diferenciá-las de cidades de porte médio. Tal conceituação é atribuída, em síntese, de acordo com os papéis de intermediação na rede urbana desempenhadas por estas cidades e, por conseguinte, das suas relações com outras cidades.

Esses são apenas alguns dos desafios presentes nos diversos trabalhos acadêmicos mencionados anteriormente. Mas o principal é que esse conjunto de ensaios acerca das cidades pequenas possibilitam alguns avanços na construção de um pensamento sobre essas cidades e na constituição de uma agenda comum sobre o tema. Primeiro, porque demonstra uma série de possibilidades e perspectivas analíticas nas quais essas investigações podem seguir. Segundo, por elucidar uma série de desafios teórico-conceituais e metodológicos. E terceiro, porque indica as principais preocupações científicas sobre as cidades pequenas.

\section{Duas formas de olhar para as cidades pequenas}

Diante do levantamento efetuado é possível identificar dois eixos analíticos mais comumente utilizados nos estudos acerca das cidades pequenas. O primeiro com foco na análise interurbana, nos quais se prioriza o estudo da rede urbana e das relações com a região, com outras cidades ou com o campo. O segundo volta-se mais para a dinâmica intraurbana, envolvendo questões referentes ao mercado imobiliário, à morfologia, às funções e ao crescimento. 
Apesar de se distinguirem, do ponto de vista analítico, os dois eixos aplicados na interpretação das cidades pequenas se complementam. Afinal, contribuem para explicar como o espaço é produzido, ocupado e organizado socialmente. Assim, como cabe a Geografia um papel primordial quando se trata de analisar e compreender a organização do espaço, estes dois eixos analíticos são respaldo para o entendimento da organização espacial e econômica da urbanização.

\section{Os efeitos externos na compreensão das cidades pequenas}

Dos diversos trabalhos sobre cidades pequenas, a grande maioria procura identificar a natureza e o significado dos papéis urbanos assumidos por estas realidades. Para tanto os pesquisadores fazem uso da análise da rede urbana, que subsidia 0 entendimento dos processos ligados à economia, à urbanização, à divisão territorial do trabalho e aos aspectos funcionais.

Nessa direção, os trabalhos geográficos que assumem esta perspectiva analítica avaliam, sobretudo, o grau de subordinação destas cidades em relação à região na qual se localiza. Além de a localização geográfica despontar como fator primordial, a tendência desta corrente é efetuar uma análise pautada nas características das atividades econômicas desenvolvidas, no tamanho e na espacialização demográfica.

Bernardelli (2000; 2002), Borges (2002), Engel (2002), Engel e Soares (2004),
Leão e Sposito (2006), Bernardelli e Matushima (2008), Castilho e Chaveiro (2008), Casaril (2010), Chagas (2010), Almeida (2010), são alguns exemplos que discutem os papéis e as redefinições dos papéis urbanos a partir de uma análise da rede urbana. A partir das características desta, os pesquisadores apontam diferentes características da natureza e das especificidades da rede urbana brasileira. Ao mesmo tempo apresentam as tendências atuais da atuação dos diversos atores sociais e dos interesses econômicos na produção do espaço urbano em cidades pequenas, bem como as dinâmicas que redefinem as práticas socioespaciais no campo e na cidade.

Tanto por meio da identificação dos papéis urbanos e da funcionalidade dos centros urbanos quanto embasados pela diferenciação do conceito de cidade local (SANTOS, 1982; 1994), alguns trabalhos se empenham em realizar uma discussão teórico-conceitual acerca das cidades pequenas, como os esforços de Gonçalves e Costa (2004); Medeiros et. al. (2008), Pereira (2008), Queiroz (2008), Roma (2008), Casaril (2010) e Fresca (2010).

Apreender sobre as cidades a partir da rede urbana e no contexto regional faz pensar também nas escalas, nos atores e nos dilemas do planejamento e da gestão do território. Sob essa perspectiva, Bacelar (2008), procurou examinar a relação entre poder público e população em cidades pequenas. Numa abordagem dos problemas que transcendem a questão financeira e ambiental, o autor considera a atuação da administração pública e a construção de um estado de bem estar social em seu referencial empírico. 
Ainda sob esse viés, surge a necessidade de se pensarem soluções de planejamento urbano e regional próprios para atender as especificidades das cidades pequenas. Nessa direção, podemos observar alguns trabalhos que se empenharam na análise do planejamento, das políticas públicas e da gestão do território na escala regional, como em Gomes et al. (2004; 2006).

Miyazaki (2010) serviu-se da rede urbana para analisar a formação de uma aglomeração urbana na região de Presidente Prudente-SP, na qual identificou a interação espacial entre uma cidade média e cidades pequenas. Já Roma (2008) a utilizou para formular a hipótese de constituição de uma segregação socioespacial interurbana. Dentre os indicadores verificados na análise da rede urbana em seu objeto de estudo, a pesquisadora considerou o fato de se tratar de uma cidade local; a dependência das relações interurbanas para suprir as necessidades de acesso aos meios de consumo coletivo e privado; e a presença de elementos que levam ao questionamento do caráter urbano da cidade. Estes elementos observados permitiram confirmar a existência, entre as cidades por ela analisadas, de uma segregação que transcende os limites do espaço urbano.

Sendo assim, os efeitos externos das cidades pequenas são fundamentais para o seu entendimento no contexto regional. Desse modo, a rede urbana assume papel central na interpretação dessas realidades urbanas e subsidia a compreensão da dinâmica interna do tecido urbano, suas configurações e transformações.

\section{A dinâmica intraurbana e sua interpretação no estudo das cidades pequenas}

Alguns aspectos despontam na apreciação da dinâmica interna das cidades pequenas. O primeiro é a articulação entre o urbano, o rural e o agrícola. Não raramente, o setor primário possui relevância significativa no conjunto das atividades econômicas desenvolvidas. A estrutura dos municípios está ligada essencialmente às atividades agropecuárias, principalmente quando nos referimos as cidades pequenas de regiões não metropolitanas.

A forte relação estabelecida entre as cidades pequenas e o campo induz a pensar sobre a pluralidade do que se pode considerar cidade e urbano no Brasil. Por exemplo, nas cidades paulistas de Osvaldo Cruz e Mariápolis, estudadas por Roma (2008), de que se avaliam qualificativos que compõem o limiar entre cidade e não cidade. Ainda sob essa perspectiva, Bernardelli (2000; 2002; 2004) destaca, a partir da análise de seu referencial empírico - as cidades pequenas da região de Catanduva-SP -, que, apesar de essas cidades se revelarem parte do espaço urbano, em razão de nelas estar ausente muito do que hoje caracteriza o urbano, também o negam.

Essa discussão sobre o caráter urbano das cidades pequenas pode ser notada ainda nos trabalhos de Lopes (2006), Queiroz (2008) e Silva, L. (2010). Os três pesquisadores identificam a estreita relação existente entre cidade e campo, na qual atividades não urbanas tomam forma nas cidades e se materializam tanto em seu espaço físico quanto nas ações contidas no plano imaterial, como costumes, hábitos e pensamentos. 
O segundo aspecto que envolve o pensamento sobre a dinâmica urbana está ligada as questões demográficas e aos movimentos migratórios que o engendram. Lisboa (2008) aborda os efeitos migratórios na realidade brasileira, considerando a migração do campo para a cidade (particularmente a pequena), a migração cidade-cidade (em especial da pequena para as maiores) e os motivos que contribuem para a não migração.

Modificações nos conteúdos das relações produtivas e sociais no campo se intensificaram, expulsando o camponês e o pequeno produtor rural em direção as cidades. Nesta direção, as cidades pequenas, muitas vezes, representam um caráter temporário para muitos, se considerarmos a ocorrência da chamada migração em etapa, como salienta Endlich (2006).

De qualquer maneira esta espécie de migração denuncia um duplo processo. No primeiro ocorre a desterritorialização do camponês ou do pequeno proprietário. Já o segundo é marcado por uma reterritorialização precária nas áreas periféricas das cidades, atribuindo a elas um papel residencial (BERNARDELLI, 2000; 2002; 2004).

Os desdobramentos dos processos migratórios são diversos, sendo que, em geral, nas cidades pequenas tem contribuído para intensificar as desigualdades sociais e espaciais. As cidades pequenas apresentam graves problemas socioespaciais, de diferente natureza. Nesta direção, diversos trabalhos visam identificar os problemas urbanos, principalmente a partir da análise da qualidade de vida, dos indicadores sociais e econômicos (CAVALCANTE, 2010) ou da segregação socioespacial (ROMA, 2006; 2008; VIEIRA, 2010).

Exemplificações acerca da problemática habitacional e da (re)produção da moradia podem ser examinadas em Matushima e Bernardelli (2008), Bernardelli (2000; 2002; 2004), Domingues et al. (2006) e Moreira Junior (2010). Nesses, se verifica como a localização e a distribuição das moradias pela cidade são entendidas no contexto do urbano como um todo e na articulação das práticas dos agentes produtores da cidade.

A abordagem do planejamento e da gestão do espaço urbano também está presente nos estudos acerca das cidades pequenas. Muitos trabalhos examinados procuram avançar nesta direção, como em Delfino e Dias (2006), Dias (2010), Gomes et al. (2004; 2006), Silva, A. B. (2006) e Silva, L. (2010). Esses autores trazem ao debate diversas contribuições sobre a gestão compartilhada dos espaços e as possibilidades de políticas voltadas para 0 planejamento urbano e regional de áreas não metropolitanas.

Contudo, diversas possibilidades, desafios e incertezas rondam os tópicos do planejamento e da gestão do território no cenário nacional. Como uma das possibilidades para ultrapassar alguns dos entraves, Chagas et al. (2000); Rossi e Martinuci (2008) e Martinuci (2010), colocam o geoprocessamento como um instrumento valioso e prático para a gestão municipal em cidades pequenas. Adiciona-se, ainda, a emergência de uma preocupação ambiental nas questões sociais das cidades, atreladas a produção, planejamento e gestão do espaço urbano. 
Nessa direção, dentre os trabalhos analisados, apenas três envolve a relação entre ambiente e sociedade. Destes, dois estão relacionados a climatologia. Enquanto Fante (2010) traz uma análise climática de cidades denominadas de pequenas, mas que na verdade apresentam populações acima de 100 mil habitantes, Silva, A. L. et al. (2002) procura conhecer o clima e a realidade das cidades pequenas, na região sudoeste de Mato Grosso. O outro ensaio representa uma preocupação com a sustentabilidade ambiental. Michelotto et al. (2002), visa compreender as novas especificidades da cidade de Estrelado Sul-MG sob o viés da sustentabilidade socioambiental.

Em suma, fica claro que refletir sobre a dinâmica interna das cidades pequenas engloba pensar os conteúdos sociais, políticos, econômicos e ideológicos presentes no processo de produção e transformação do espaço urbano. Desse modo, modificações na morfologia e nos conteúdos sociais são adicionados ao espaço urbano das cidades pequenas. Recebem formas, objetos, conteúdos e problemas (violência, insegurança, drogas, pressão imobiliária, favelização etc.), que não até então não faziam parte da sua paisagem. Exemplos disto são cidades pequenas que apresentam índices elevados de violência; aquelas que atualmente abrigam presídios gerando, dentre outros, problemas de segurança; as que já evidenciam o aparecimento de favelas ou áreas de ocupação irregular; além de outros diversos problemas econômicos e sociais. Este conjunto de cidades representam, portanto, espaços muito mais complexos e heterogêneos do que se pode inferir.

\section{Considerações finais}

A delimitação das cidades pequenas deve ir além de dados quantitativos - como os demográficos, de desenvolvimento econômico e social, entre outros -, devendo, sobretudo, considerar também os aspectos qualitativos, como por exemplo, sobre suas características, seus cotidianos, suas funções e suas formas.

Construir um pensamento a respeito das cidades pequenas requer um pensamento muito mais amplo que perpassa por uma reflexão sobre a cidade e o urbano, bem como pelo entendimento dos processos atrelados a economia e a urbanização brasileira. A tentativa de estabelecer uma classificação ou uma conceituação à cidade pequena é uma tarefa bastante difícil e complexa, devido, sobretudo, a heterogeneidade destas realidades urbanas.

Nessa direção, a proposta do levantamento do que tem sido produzido na área geográfica no Brasil - tendo por base os anais dos ENGs - permite observar o modo que se tem desenrolado as discussões sobre o tema, os conceitos que são abordados, os recortes espaciais e os referenciais empíricos envolvidos em cenários diferenciados. Ao mesmo tempo em que evidenciam os variados olhares sobre as cidades pequenas, especialmente no que diz respeito as bases lógicas da investigação científica. Reconhecer estes fundamentos e teorias acerca da natureza do espaço urbano em cidades pequenas permite promover uma visão crítica e proporciona uma reflexão dos principais problemas que nelas se manifestam.

Apesar de se notar um avanço em pesquisas sobre cidades pequenas no Brasil, uma série de desafios e incertezas ainda 
permeia o debate. A carência ou insuficiência do pensar científico sobre as cidades pequenas precisa ser corrigida por pesquisas teórico-conceituais e empíricas que tanto façam abordagens comparativas quanto estabeleçam uma agenda comum de pesquisa para a compreensão das cidades e da vida urbana. A questão ainda parece estar em aberto, apesar de sua importância no quadro da urbanização brasileira.

\section{Referências bibliográficas}

ALMEIDA, A. P. Produção industrial em pequenas cidades e reinserções na rede urbana: o caso de Assaí-PR. Anais XVI ENG. Porto Alegre, 2010. CD Rom.

ANDRADE, M. A. A. Transformações em curso no perfil econômico e socioespacial de cidades de pequeno porte: o exemplo de Bom Jesus de Itabapoana no noroeste fluminense. Dissertação (Mestrado em Geografia) Universidade Federal do Rio de Janeiro, Rio de Janeiro, 2001.

BACELAR, W. K. A. Pequena cidade: caracterização e conceituação pelo ponto de vista político-administrativo. Anais XVI ENG. Porto Alegre, 2010. CD Rom.

. A pequena cidade nas teias da aldeia global: as relações e especificidades sócio-políticas nas pequenas cidades de Estrela do Sul, Cascalho Rico e GrupiaraMG. Tese (Doutorado em Geografia) - Universidade Federal de Uberlândia, Uberlândia, 2008.

BernaRdelli, M. L. F. H. Pequenas cidades na região de CatanduvaSP: papéis urbanos, reprodução social e produção de moradias. Tese (Doutorado em Geografia) Universidade Estadual Paulista, Presidente Prudente, 2004.

; MATUSHIMA, M. K. Pequenas cidades no vale do Ivinhema-MS: papéis urbanos, reprodução social e produção de moradias. Anais XV ENG. São Paulo, 2008. CD Rom.

BORGES, G. V.; SOARES, B. R. Cidades locais do cerrado mineiro: uma leitura preliminar. Anais XVI ENG. Porto Alegre, 2002. CD Rom.
BRIDI, J.; SOARES, B. R. A modernidade nos espaços rural e urbano das pequenas cidades do cerrado mineiro: estudo em Tupaciguara - Minas Gerais. Anais VII Congresso Brasileiro de Geógrafos. Goiânia, 2004. CD Rom.

CASARIL, C. C. Pequenas cidades ou cidades locais? Por uma perspectiva teórico-metodológica atual. Anais XVI ENG. Porto Alegre, 2010. CD Rom.

CASTILHO, D.; CHAVEIRO, E. F. Cidade e dinâmica cultural: o contexto das cidades locais da microrregião Ceres, Goiás. Anais XV ENG. São Paulo, 2008. CD Rom.

CAVAlCANTE, C. M. Perfil socioeconômico das cidades pequenas do seridó ocidental da Paraíba. Anais XVI ENG. Porto Alegre, 2010. CD Rom.

CHAGAS, J. B.; ASSUNÇÃO, V. S.; ARAÚJO, W. T.; SANTOS, R. L. O geoprocessamento como ferramenta de gestão urbana de cidades pequenas. Anais XII ENG. Florianópolis, 2000. CD Rom.

CHAGAS, S. E. A. Pequenas cidades e produção territorial: elementos para a discussão geográfica. Anais XVI ENG. Porto Alegre, 2010. CD Rom.

CORRÊA, R. L. As pequenas cidades na confluência do urbano e do rural. Geousp. São Paulo, n. 30, p. 5-12, 2011.

CRIVELARO, S. H. R. Espaço vivido, cotidiano e qualidade de vida em pequenos municípios: caso: município de Urupês (SP). Dissertação (Mestrado em Geografia) - Universidade Estadual de Campinas, Campinas, 2008.

DEFILIPPO, A.; PAULA, A. M.; FERREIRA FILHO, N.; SOARES, R. A. Astolfo Dutra: dinâmica industrial de uma 
cidade local. Anais XV ENG. São

Paulo, 2008. CD Rom.

DELFINO, D. S.; DIAS, V. L. N. Um olhar sobre a urbanização, seus problemas e o planejamento das cidades locais. Estudo de caso da cidade de Jaguaruna/SC. Anais XIV ENG. Rio Branco, 2006. CD Rom.

DIAS, A. C. J. Reflexões sobre o papel do planejamento urbano na pequena cidade de Rio de Contas/BA. Anais XVI ENG. Porto Alegre, 2010. CD Rom.

DOMINGUES, A. T.; CAVALI, A. P.; CALIXTO, M. J. M. O processo de redefinição do espaço urbano em uma cidade de pequeno porte: uma análise do Conjunto Habitacional Catulino Rodrigues de Lima em Rio Brilhante/MS. Anais XIV ENG. Rio Branco, 2006. CD Rom.

ENDLICH, A. M. Pensando os papéis e significados das pequenas cidades do noroeste do Paraná. Tese (Doutorado em Geografia) Universidade Estadual Paulista, Presidente Prudente, 2006.

. Rede urbana, urbanidades e as pequenas cidades: ensaiando a discussão. Anais XVI ENG. Porto Alegre, 2002. CD Rom.

; ROCHA, M. M. (Orgs.). Pequenas cidades e desenvolvimento local. Maringá: PGE, 2009.

ENGEL, A. S.; SOARES, B. R. A dinâmica urbana das pequenas cidades do cerrado mineiro e sua participação na rede urbana regional. Anais VII Congresso Brasileiro de Geógrafos. Goiânia, 2004. CD Rom.

ENGEL, A. S.; BESSA, K. C. F. O.; SOARES, B. R. A importância das cidades medias e locais na dinâmica urbana da bacia do rio Araguari-Minas Gerais. Anais XVI ENG. Porto Alegre, 2002. CD Rom.

FABRINI, J. E. A reprodução contraditória do rural nas cidades pequenas. Terra Livre, v. 1 , n. 32 , p. 137-152, jan./jun. 2009.

FANTE, K. P. Análise da variabilidade termal nas cidades de pequeno e médio porte paulista: o caso de Presidente
Prudente e Votuporanga-SP (19762009). Anais XVI ENG. Porto Alegre, 2010. CD Rom.

Figueiredo, V. D. M. Pequenos municípios e pequenas cidades do estado do Rio Grande do Sul: contrastes, perfil do desenvolvimento e de qualidade de vida, 1980-2000. Tese (Doutorado em Geografia) Universidade Estadual Paulista, Rio Claro, 2008.

FRESCA, T. M. Centros locais e pequenas cidades: distinções necessárias.

Anais XVI ENG. Porto Alegre, 2010. CD Rom.

GOMES, R. C. C.; BARBOSA, A.; SILVA, V. P. Planejamento, gestão do território e desenvolvimento socioespacial das pequenas cidades do Rio Grande do Norte. Anais XIV ENG. Rio Branco, 2006. CD Rom.

Gestão pública nas pequenas cidades do Rio Grande do Norte na era da informação. Anais VII Congresso Brasileiro de Geógrafos. Goiânia, 2004. CD Rom.

GONÇALVES, F. E.; COSTA, A. A. Para entender as cidades pequenas: contribuições para o debate. Anais VII Congresso Brasileiro de Geógrafos. Goiânia, 2004. CD Rom.

LAHORGUE, M. L.; GOULART, E. F. M.; FELÁCIO, R. M. Existe segregação socioespacial em municípios pequenos? O caso de Forquilhinha (SC). Anais XV ENG. São Paulo, 2008. CD Rom.

LEÃO, C. S. ; SPOSITO, E. S. A dinâmica econômica em cidades pequenas: estudo de caso de Ouro Verde/SP. Anais XIV ENG. Rio Branco, 2006. CD Rom.

LOPES, D. M. F. L. Cidades pequenas não devem ser consideradas urbanas? O caso de Novo Triunfo/Bahia. Anais XIV ENG. Rio Branco, 2006. CD Rom.

; HENRIQUE, W. (Orgs.). Cidades médias e pequenas: teorias, conceitos e estudos de caso. Salvador: SEI, 2010.

MARTINUCI, O. S. O uso das ferramentas de geoinformação nas políticas públicas 
sociais em municípios de pequeno porte, Anais XVI ENG. Porto Alegre 2010. CD Rom.

MEDEIROS, D. A.; CARVALHO, T. A. P.; CARVALHO, A. A. T. Reconstituindo o estudo das cidades de pequeno porte na Geografia urbana brasileira. Anais XV ENG. São Paulo, 2008. CD Rom.

MELO, N. A. Pequenas cidades da microrregião geográfica de Catalão (GO): análise de seus conteúdos e considerações teórico-metodológicas. Tese (Doutorado em Geografia) - Universidade Federal de Uberlândia, Uberlândia, 2008.

; SOARES, B. R. Pequenas cidades da microrregião de Catalão (GO): papel dos processos de "modernização" econômica na dinâmica urbana.

Anais XV ENG. São Paulo, 2008. CD Rom.

MICHELOTTO, B. G.; GROSSI, S. R.; SOARES, B. R. A cidade pequena e sua participação na organização espacial regional: um estudo de sustentabilidade ambiental em Estrelado Sul-MG. Anais XVI ENG. Porto Alegre, 2002. CD Rom.

MIYAZAKI, V. K. Interações espaciais em cidades pequenas e médias: o caso do processo de aglomeração urbana. Anais XV ENG. São Paulo, 2008. CD Rom.

MOREIRA JUNIOR, O. Produção do espaço urbano, reprodução social da moradia e desigualdades socioespaciais em cidades pequenas paulistas: os casos de Capão Bonito e Buri. Anais XVI ENG. Porto Alegre, 2010. CD Rom.

OLIVEIRA, B. S.; SOARES, B. R. Cidades locais: importância para o desenvolvimento do Triângulo Mineiro e Alto Paranaíba-MG. Anais XII ENG. Florianópolis, 2000. CD Rom.

PEREIRA, A. M. Existe segregação socioespacial em municípios pequenos? O caso de Forquilhinha (SC). Anais XV ENG. São Paulo, 2008. CD Rom.

QUEIROZ, M. A. Entre o rural e o urbano: cidades locais no Consad Paraná Centro-PR. Anais XV ENG. São Paulo, 2008. CD Rom.
ROMA, C. M. Segregação socioespacial em cidades pequenas. Dissertação (Mestrado em Geografia) Universidade Estadual Paulista, Presidente Prudente, 2008a.

. Segregação socioespacial interurbana: uma hipótese? Terra Livre, v. 2, n. 31, p. 111-132, jul./dez. 2008b.

. Segregação socioespacial em cidades pequenas. Anais XIV ENG. Rio Branco, 2006. CD Rom.

ROSSI, R.; MARTINUCI, O. S. Processos excludentes em pequenas cidades paulistas - a modelização cartográfica em Álvares Machado-SP. Anais XV ENG. São Paulo, 2008. CD Rom.

SANT'ANA, M. J. R. A questão do lugar para a compreensão da vida cotidiana em Regente Feijó: uma análise em cidades pequenas. Anais VII Congresso Brasileiro de Geógrafos. Goiânia, 2004. CD Rom.

SANTOS, M. A urbanização brasileira. São Paulo: Hucitec, 1994.

. Espaço e sociedade. Petrópolis: Vozes, 1982.

SANTOS, P. G. S. Territorialidades e espaço público em pequenas cidades da fronteira amazônica: reflexões sobre Oiapoque-AP . Anais XVI ENG. Porto Alegre, 2010. CD Rom.

SILVA, A. B. A gestão do território no contexto da redemocratização do Brasil: um olhar sobre as pequenas cidades do cariri paraibano. Anais XIV ENG. Rio Branco, 2006. CD Rom.

SILVA, A. L.; SANTOS, P. C. B.; CANARGO, S. C.; SETTE, D. M. O clima das cidades tropicais de pequeno porte na região sudoeste de Mato Grosso: Pedra Preta, Dom Aquino e Guiratinga. Anais XVI ENG. Porto Alegre, 2002. CD Rom.

SILVA, G. K. N. O uso do espaço pelas vaquejadas em cidades pequenas: o caso de Santo Antônio no Rio Grande do Norte. Anais XVI ENG. Porto Alegre, 2010. CD Rom. 
SILVA, L. F. P. M. Os rondonistas e os desafios na elaboração de propostas de contribuição para o plano diretor de pequenas cidades do interior do país. Anais XVI ENG. Porto Alegre, 2010. CD Rom.

SILVEIRA, G. S. O turismo como subsídio para o desenvolvimento de pequenas cidades do norte de Minas Gerais.

Anais XVI ENG. Porto Alegre, 2010. CD Rom.
VEIGA, L. A.; FRESCA, T. M. Serviços especializados como nova inserção na divisão do trabalho em pequenas cidades: o caso de Santa Fé-PR. Anais XVI ENG. Porto Alegre, 2010. CD Rom.

VIEIRA, J. R. S. Segregação em pequenas cidades: um estudo de caso na cidade de Anadia Alagoas. Anais XVI ENG. Porto Alegre, 2010. CD Rom. 